\title{
Mammography Rates 3 Years After the 2009 US Preventive Services Task Force Guidelines Changes
}

\section{Citation}

Wharam, J. Frank, Bruce Landon, Fang Zhang, Xin Xu, Stephen Soumerai, and Dennis RossDegnan. 2015. "Mammography Rates 3 Years After the 2009 US Preventive Services Task Force Guidelines Changes." Journal of Clinical Oncology 33 (9) (March 20): 1067-1074. doi:10.1200/ jco.2014.56.9848.

\section{Published Version}

doi:10.1200/JC0.2014.56.9848

\section{Permanent link}

http://nrs.harvard.edu/urn-3:HUL.InstRepos:32692586

\section{Terms of Use}

This article was downloaded from Harvard University's DASH repository, and is made available under the terms and conditions applicable to Other Posted Material, as set forth at http:// nrs.harvard.edu/urn-3:HUL.InstRepos:dash.current.terms-of-use\#LAA

\section{Share Your Story}

The Harvard community has made this article openly available.

Please share how this access benefits you. Submit a story.

\section{Accessibility}


All authors: Harvard Medical School; J. Frank Wharam, Fang Zhang, Xin Xu, Stephen Soumerai, and Dennis RossDegnan, Harvard Pilgrim Health Care Institute, Boston, MA.

Published online ahead of print at www.jco.org on February 9, 2015

Supported by Grant No. 118261-RSGI10-075-01-CPHPS from the American Cancer Society.

Presented in part at the 36th Annual Meeting of the Society of General Internal Medicine, April 24-27, 2013, Denver, CO; Academy Health Annual Research Meeting, June 23-25, 2013, Baltimore, MD; 37th Annual Meeting of the Society of General Internal Medicine April 23-26, 2014, San Diego, CA; and Academy Health Annual Research Meeting, June 8-10, 2014, San Diego, CA.

Authors' disclosures of potential conflicts of interest are found in the article online at www.jco.org. Author contributions are found at the end of this article.

Corresponding author: J. Frank Wharam, MB, BCh, BAO, MPH, Department of Population Medicine, Harvard Medical School and Harvard Pilgrim Health Care Institute, 133 Brookline Ave, 6th Floor, Boston, MA 02114; e-mail: jwharam@post.harvard.edu.

C 2015 by American Society of Clinical Oncology

0732-183X/15/3309w-1067w/\$20.00 DOI: $10.1200 / J C O .2014 .56 .9848$

\title{
Mammography Rates 3 Years After the 2009 US Preventive Services Task Force Guidelines Changes
}

\author{
J. Frank Wharam, Bruce Landon, Fang Zhang, Xin Xu, Stephen Soumerai, and Dennis Ross-Degnan
}

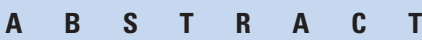

\section{Purpose}

In November 2009, the US Preventive Services Task Force (USPSTF) changed its mammography recommendations from every 1 to 2 years among women age $\geq 40$ years to personalized screening decisions for women age 40 to 49 years and screening every 2 years for women age 50 to 74 years

\section{Methods}

We studied mammography trends among 5.5 million women age 40 to 64 years enrolled in a large national health insurer. We used 2005 to 2009 mammography trends to predict 2012 rates. Our primary measure was the estimated difference between observed and predicted 2012 annual and biennial mammography rates. We stratified results by age group and race/ethnicity.

\section{Results}

Among women age 40 to 49 years, 2012 mammography rates declined by $9.9 \%(95 \% \mathrm{Cl}$, $-10.4 \%$ to $-9.3 \%$ ) relative to the predicted 2012 rate. Decreases were lowest among black women $(-2.3 \% ; 95 \% \mathrm{Cl},-6.3 \%$ to $1.8 \%)$ and highest among Asian women $(-17.4 ; 95 \% \mathrm{Cl}$, -20.0 to -14.8 ). Annual mammography rates among women age 50 to 64 years declined by $6.1 \%(95 \% \mathrm{Cl},-6.5 \%$ to $-5.7 \%)$ by 2012 . Regarding biennial mammography rates, women age 40 to 49 years experienced a $9.0 \%$ relative reduction $(95 \% \mathrm{Cl},-9.6 \%$ to $-8.4 \%)$. White, Hispanic, and Asian women age 40 to 49 years demonstrated similar relative reductions of approximately $9 \%$ to $11 \%$, whereas black women had no detectable changes $10.1 \% ; 95 \% \mathrm{Cl}$, $-4.0 \%$ to $4.3 \%)$. Women age 50 to 64 years had a $6.2 \%$ relative reduction $(95 \% \mathrm{Cl},-6.6 \%$ to $-5.7 \%$ ) in biennial mammography that was similar among white, Hispanic, and Asian women. Black women age 50 to 64 years did not have changes in biennial mammography $(0.4 \% ; 95 \% \mathrm{Cl},-2.6 \%$ to $3.5 \%)$.

\section{Conclusion}

Three years after publication of the 2009 USPSTF guidelines, mammography rates declined by $6 \%$ to $17 \%$ among white, Hispanic, and Asian women but not among black women. Small reductions in biennial mammography might be an unintended consequence of the updated guidelines.

\section{J Clin Oncol 33:1067-1074. (C) 2015 by American Society of Clinical Oncology}

\section{INTRODUCTION}

Breast cancer is the leading cause of cancer among women, with an incidence of 121.9 per 100,000 and a death rate of 22.6 per 100,000 from 2006 to $2010 .{ }^{1}$ Mortality is substantially higher among black women than among white, Hispanic, and Asian women. ${ }^{1}$ The effect of mammography on breast cancer mortality is controversial. Although early detection and treatment of aggressive breast cancers reduce the risk of premature mortality, ${ }^{2-10}$ a recent Cochrane review concluded that mammograms often detect nonfatal breast cancer types and that rigorous studies did not detect a mortality benefit. ${ }^{11}$ The Canadian National Breast Screening Study sim- ilarly detected no mortality benefit and estimated an overdiagnosis rate of $22 \%$. $^{12}$

Appropriate breast cancer screening intervals and age of initiation are also controversial. ${ }^{13,14}$ Some authorities believe that overuse of mammography creates unacceptably high rates of anxiety, falsepositive detection, and morbidity as a result of unneeded procedures. ${ }^{15-18}$ Others counter that underuse causes preventable deaths. ${ }^{13,14}$ Before 2010, the US Preventive Services Task Force (USPSTF) recommended screening mammography every 1 to 2 years for women age 40 and older. ${ }^{19}$ Updated USPSTF guidelines published in November 2009 recommend individual screening decisions for women age 40 to 49 years that "take patient context 
into account, including the patient's values regarding specific benefits and harms" and advocate screening every 2 years for women age 50 to 74 years. ${ }^{15}$ Most other US guidelines continue to recommend mammography either annually or biennially after age 39 years, ${ }^{20-24}$ whereas guidelines from Europe and Canada are more closely aligned with USPSTF recommendations. ${ }^{25,26}$

The release of the USPSTF guidelines generated major controversy and media attention ${ }^{27-30}$ that might have affected women's attitudes about mammography and changed screening patterns. Evidence of the impact of the USPSTF recommendations is scant and mixed, with smaller studies showing either no changes ${ }^{31,32}$ or modest reductions in screening rates. ${ }^{33,34}$ We examined breast cancer screening rates before and after the 2009 guideline changes by age and race/ethnicity group in a large commercially insured population.

\section{METHODS}

\section{Data Sources}

We studied enrollment information and 2005 to 2012 administrative claims data (the Optum Clinformatics Data Mart data set; Optum, Eden Prairie, MN $)^{35}$ from a large national health plan with members in all 50 US states. We linked sociodemographic variables derived from the 2000 US census using block group code of residence. We had an ethnicity variable derived from surname analysis.

\section{Study Population}

We included commercially insured women age 40 to 64 years with at least 11 months of continuous enrollment between 2005 and 2012 and no evidence of previous mastectomy based on Current Procedural Terminology and International Classification of Diseases, Ninth Revision procedure codes (Appendix Table A1, online only).

\section{Outcomes}

We generated quarterly and annual screening rates for all eligible women and biennial rates for women with at least 23 months of continuous enrollment. We defined women as screened for breast cancer if they had at least one mammography claim during a given interval based on Current Procedural Terminology, Healthcare Common Procedure Coding System, and International Classification of Diseases, Ninth Revision codes (Appendix Table A1). Similar to measures used in standardized reporting systems, such as the Healthcare Effectiveness Data and Information Set, ${ }^{36}$ this measure comprised codes for both screening and diagnostic mammograms. We included both types because a woman who receives either is considered screened for breast cancer for the subsequent 1 to 2 years, because providers ordering such tests might not appropriately distinguish differences or might be influenced by reimbursement rates, and because policy changes can be associated with changes in coding practices. The denominator for each woman was the proportion of the quarter, calendar year, or 2-calendar year period in which she was enrolled. A woman enrolled for 21 months (out of 24) in a 2-calendar year period would have a denominator of $21 / 24$, or 0.88 , rather than $24 / 24$, or 1.0 .

\section{Covariates and Stratifying Variables}

We classified women as from predominantly white, black, or Hispanic neighborhoods if they lived in a census block group (geocoding) with at least $75 \%$ of members of the respective race/ethnicity. We classified members as having Asian or Hispanic ethnicity using surname analysis ${ }^{37}$ and classified remaining women as from mixed-race/ethnicity neighborhoods. Geocoding is sensitive in detecting black or white race, and surname analysis provides accurate information on Asian and Hispanic ethnic group. ${ }^{38}$ This validated approach of combining surname analysis and census data has positive and negative predictive values of approximately $80 \%$ and $90 \%$, respectively. ${ }^{38} \mathrm{We}$ classified women during any given period as age 40 to 49 years or 50 to 64 years.
We removed $0.6 \%$ of eligible women because of missing geocoded values. We also classified members by the region of the country in which they resided (Northeast, South, West, and Midwest). Other covariates included age, neighborhood poverty level (classified as residence in neighborhoods with below poverty levels of $<5 \%, 5 \%$ to $9.9 \%, 10 \%$ to $19.9 \%$, and $\geq 20 \%$ ), ${ }^{39}$ and neighborhood education level (classified as residence in neighborhoods with less than high school education levels of $<15 \%, 15 \%$ to $24.9 \%, 25 \%$ to $39.9 \%$, and $>40 \%)^{39}$

\section{Analysis}

We examined sociodemographic characteristics of the populations in 2005, 2009, and 2012. We calculated quarterly, annual, and biennial mammography rates as events per person-time. Because factors such as the major recession of December 2007 to June 2009 might have affected study sample characteristics over time, we adjusted time series rates. This involved using weights derived from the 2005 population's stratum-level characteristics (education level, poverty level, race/ethnicity, and US region) applied to subsequent screening rates. We plotted mammography rates stratified by age group and race/ethnicity, standardized for the variables that were not used to stratify.

We used interrupted time-series Poisson regression with generalized estimating equations ${ }^{40,41}$ to fit a member-level linear model to quarterly, annual, and biennial screening trends, adjusting for member characteristics including age, region of residence, poverty level, education level, and race/ ethnicity. For the annual and biennial models, we included a 2012 and 2011 to 2012 rate term, respectively, a trend term, and the covariates mentioned earlier. For the model estimating annual rates, we excluded the years 2010 and 2011, and we excluded 2009 to 2010 and 2010 to 2011 from biennial models. The value of interest was the parameter estimate of the 2012 or 2011 to 2012 time point term; the exponential of this coefficient subtracted from 1 estimates the relative reduction in the observed 2012 rate compared with the 2012 rate as predicted by the baseline trend. We also used the recycled predictions method $^{42}$ to estimate predicted and observed 2012 and 2011 to 2012 mammography rates and absolute reductions. To confirm that mammography rate changes were coincident with the publication of the USPSTF guidelines, we performed interrupted time series analysis using the quarterly rates where the term of interest was the change in the level of screening immediately after the guidelines were published (ie, beginning in quarter 1 of 2010). To test the hypothesis that mammography rates would have reached a plateau after 2009, we performed Poisson generalized estimating equations regression to examine the difference between the estimated 2009 (2008 to 2009 for biennial) and 2012 (2011 to 2012 for biennial) mammography rates, controlling for member-level covariates. We also conducted a sensitivity analysis using a mammography measure that excluded diagnostic Current Procedural Terminology and Healthcare Common Procedure Coding System mammography codes (76090, 76091, G0204, and G0206), an approach that has a 92\% positive predictive value. $^{43}$

We conducted analyses using SAS version 9.3 (SAS Institute, Cary, NC) and STATA 12.1 (StataCorp, College Station, TX). The Institutional Review Board at Harvard Pilgrim Health Care Institute (Boston, MA) approved this study.

\section{RESULTS}

Table 1 lists the characteristics of the study populations in 2005, 2009, and 2012. The cohort comprised over 2 million women per year who had median ages of 50 to 51 years over the study period; $43 \%$ to $50 \%$ were age 40 to 49 years, and $50 \%$ to $57 \%$ were age 50 to 64 years. Approximately $60 \%$ lived in high education neighborhoods, and approximately $47 \%$ lived in low poverty neighborhoods; $3 \%$ of women were from predominantly black neighborhoods, $7 \%$ to $9 \%$ had Hispanic surnames or were from Hispanic neighborhoods, approximately 3\% had Asian surnames, and 15\% were from mixed-race/ 


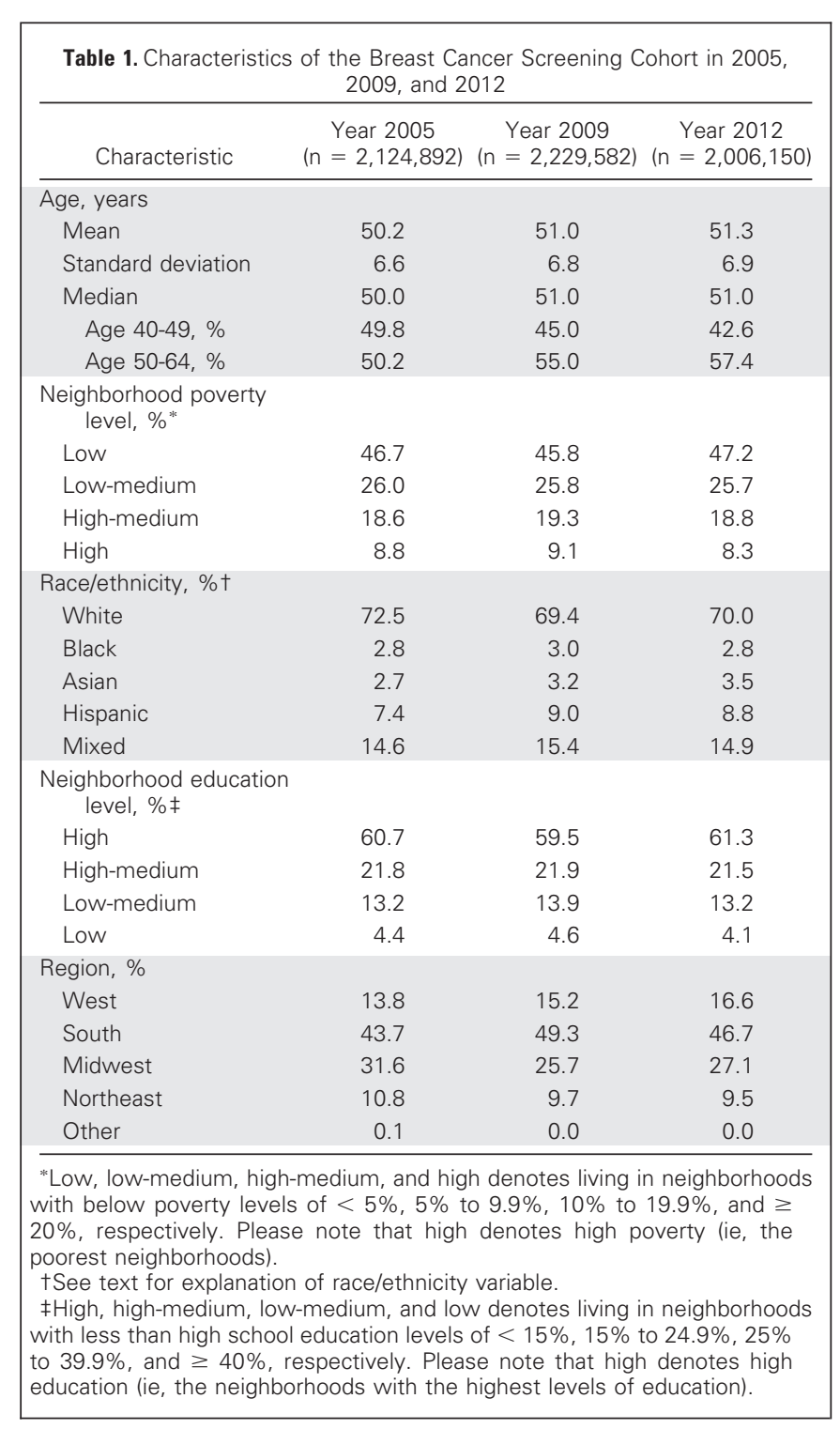

ethnicity neighborhoods. Most women were from the South and Midwest United States.

\section{Annual Screening Rates}

Figures 1 and 2 list standardized mammography rates and show plots of these rates from 2005 to 2012. The estimated observed 2012 rate was $38.8 \%$ (95\% CI, $38.6 \%$ to $39.0 \%$; Table 2$)$, whereas the predicted 2012 rate was $43.1 \%$ ( $95 \%$ CI, $43.1 \%$ to $43.2 \%$ ), a $9.9 \%$ (95\% CI, $-10.4 \%$ to $-9.3 \%$ ) relative and $4.3 \%$ (95\% CI, $-4.6 \%$ to $-4.1 \%)$ absolute reduction. Relative reductions were large among white, Hispanic, and Asian women (-9.4\% [95\% CI, $-10.1 \%$ to $-8.8 \%$ ], $-14.2 \%$ [95\% CI, $-15.9 \%$ to $-12.5 \%$ ] , and $-17.4 \%$ [95\% CI, $-20.0 \%$ to $-14.8 \%$, respectively) in this age group. Black women experienced a nonsignificant relative decrease of $2.3 \%$ (95\% CI, $-6.3 \%$ to $1.8 \%$ ). The estimated observed and predicted 2012 mammography rates among women age 50 to 64 years were $47.5 \%$ (95\% CI, $47.3 \%$ to $47.7 \%)$ and $50.7 \%$ (95\% CI, $50.6 \%$ to $50.8 \%)$, respectively, a $6.1 \%(95 \% \mathrm{CI},-6.5 \%$ to $-5.7 \%)$ relative and $3.3 \%(95 \% \mathrm{CI}$,
$-3.5 \%$ to $-3.0 \%$ ) absolute reduction. Relative reductions were again greatest among Asian women ( $-11.4 \%$; $95 \% \mathrm{CI},-14.0 \%$ to $-8.7 \%)$ and not detectable among black women $(-0.9 \%$; $95 \%$ CI, $-1.9 \%$ to $3.8 \%)$.

\section{Biennial Screening Rates}

Among women age 40 to 49 years, observed and predicted 2011 to 2012 biennial mammography rates were $65.8 \%$ (95\% CI, $65.4 \%$ to $66.1 \%$ ) and $71.9 \%$ (95\% CI, $71.8 \%$ to $72.1 \%$ ), respectively, a $9.0 \%$ (95\% CI, $-9.6 \%$ to $-8.4 \%$ ) relative and $6.2 \%$ (95\% CI, $-6.6 \%$ to $-5.7 \%$ ) absolute reduction. White, Hispanic, and Asian women age 40 to 49 years experienced similar relative reductions of $-9.8 \%$ (95\% $\mathrm{CI},-10.5 \%$ to $-9.2 \%),-9.2 \%(95 \% \mathrm{CI},-11.0 \%$ to $-7.2 \%)$, and $-10.6 \%$ (95\% CI, $-13.6 \%$ to $-7.5 \%$ ), respectively, whereas black women did not experience a relative reduction $(-0.1 \%$; $95 \% \mathrm{CI}$, $-4.0 \%$ to $4.3 \%$ ). Observed and predicted biennial mammography rates among women age 50 to 64 years were $76.5 \%$ (95\% CI, $76.1 \%$ to $76.8 \%$ ) and $81.2 \%$ (95\% CI, $81.0 \%$ to $81.3 \%$ ), respectively, a $6.2 \%$ $(95 \% \mathrm{CI},-6.6 \%$ to $-5.7 \%)$ relative and $4.7 \%$ (95\% CI, $-5.1 \%$ to $-4.3 \%$ ) absolute reduction that was similar among white, Hispanic, and Asian women. Black women age 50 to 64 years did not experience changes in biennial mammography $(0.4 \%$; $95 \% \mathrm{CI},-2.6 \%$ to $3.5 \%)$.

Quarterly interrupted time series analyses confirmed that screening rates decreased immediately after the publication of the USPSTF guidelines among women age 40 to 49 years and 50 to 64 years and in all race/ethnicity subgroups except black and Asian women age 50 to 64 years (Appendix Table A2, online only). Our sensitivity analyses examining differences between estimated 2009 and 2012 rates showed a similar pattern of statistically significant reductions across the subgroups, but their magnitude was reduced (Appendix Table A3, online only). Using a screening-specific mammography measure, we found increased relative effect sizes (ie, greater reductions in screening mammography after the USPSTF guideline changes; Appendix Table A4, online only) versus our primary analysis that included any mammogram. Notable findings from our analysis of rates by region include that women age 50-64 years in the West and Midwest experienced relative reductions in biennial screening of 9.0\% (95\% CI, $-10.3 \%$ to $-7.8 \%$; Appendix Table A5, online only) and $10.5 \%(-11.4 \%$ to $-9.7 \%)$, respectively.

\section{DISCUSSION}

Three years after publication of the 2009 USPSTF mammography guidelines, annual and biennial mammography rates decreased by $6 \%$ to $17 \%$ among women who were not from black or mixed-race neighborhoods. Reductions were generally larger among women age 40 to 49 years than women age 50 to 64 years, but annual rates declined to a similar degree compared with biennial rates. Changes also differed by race/ethnicity; reductions were generally greatest among Asian women and were not detectable among black women.

The differential reductions by age group and race/ethnicity could indicate some level of responsiveness to the USPSTF guidelines. The major media attention ${ }^{27-30}$ surrounding the guidelines might have led to changes in routine clinical protocols, stimulated discussions between providers and women, or affected mammography self-referral patterns. The guidelines recommended against routine screening among women age 40 to 49 years, and reductions were greater in this 


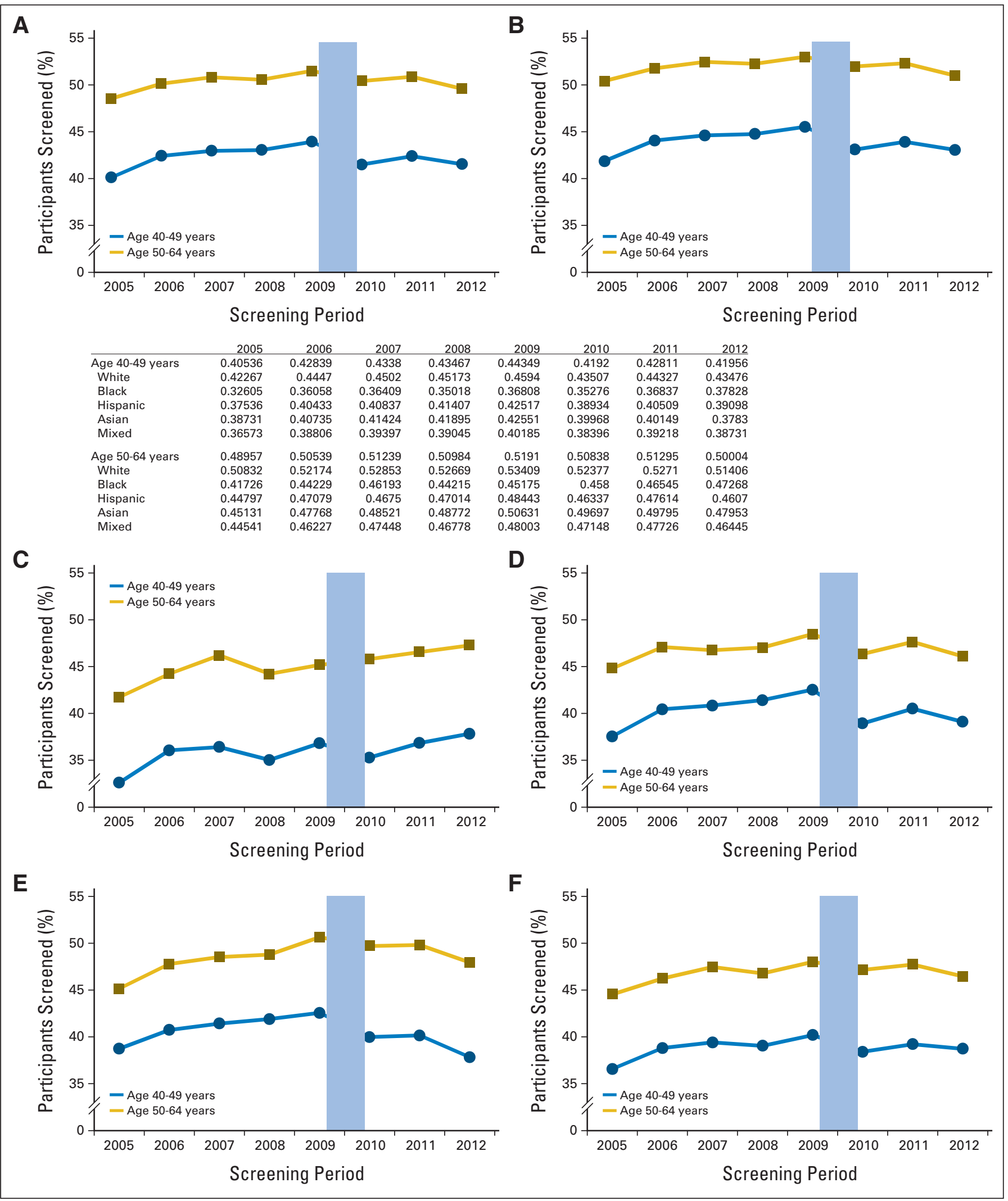

Fig 1. Adjusted annual mammography rates before and after the November 2009 US Preventive Services Task Force breast cancer screening guideline changes: (A) overall; (B) predominantly white neighborhood; (C) predominantly black neighborhood; (D) Hispanic ethnicity; (E) Asian ethnicity; and (F) mixed-race neighborhood. 
A

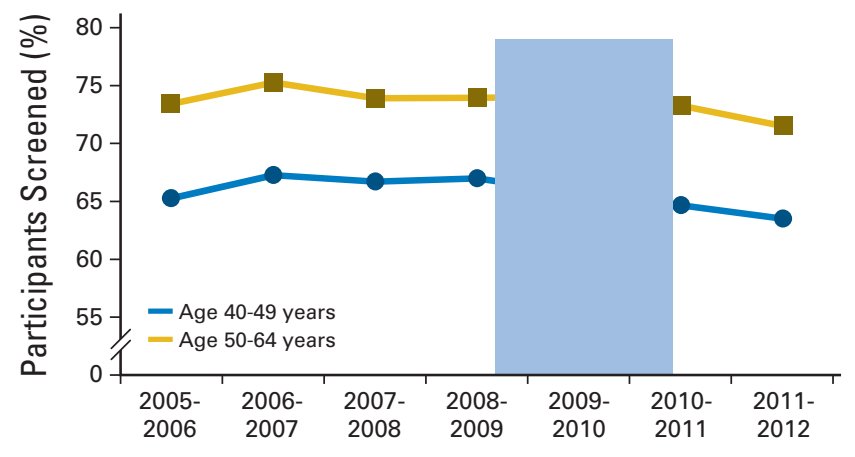

Screening Period
B

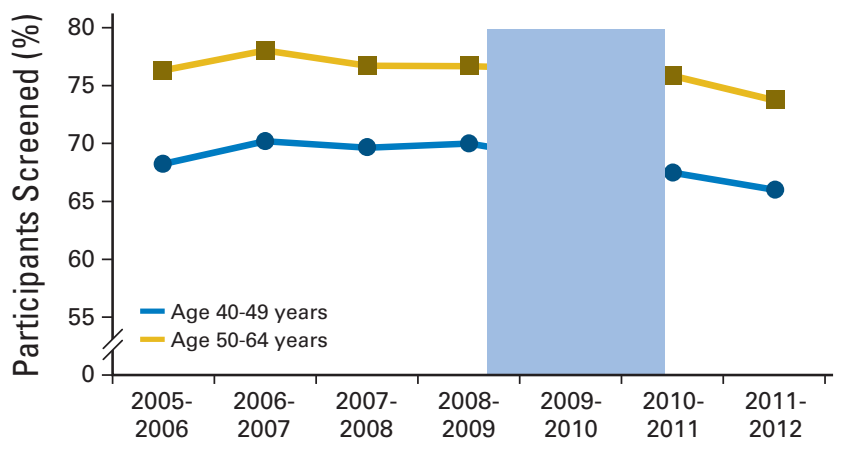

\begin{tabular}{lrrrrrrr} 
& $2005-2006$ & $2006-2007$ & $2007-2008$ & $2008-2009$ & $2009-2010$ & $2010-2011$ & $2011-2012$ \\
\hline Age 40-49 years & 0.66105 & 0.68092 & 0.67533 & 0.6784 & 0.66559 & 0.65494 & 0.64344 \\
White & 0.68184 & 0.70144 & 0.69603 & 0.6996 & 0.68467 & 0.67425 & 0.65941 \\
Black & 0.55972 & 0.58782 & 0.56697 & 0.56613 & 0.56564 & 0.56319 & 0.57483 \\
Hispanic & 0.63024 & 0.64938 & 0.65214 & 0.6564 & 0.64743 & 0.62805 & 0.6245 \\
Asian & 0.63143 & 0.65462 & 0.65049 & 0.65578 & 0.64457 & 0.63057 & 0.61282 \\
Mixed & 0.61083 & 0.63012 & 0.6208 & 0.62095 & 0.61279 & 0.60599 & 0.60201 \\
& & & & & & & \\
Age 50-64 years & 0.74263 & 0.76102 & 0.74757 & 0.74796 & 0.74861 & 0.741 & 0.72332 \\
White & 0.76269 & 0.77985 & 0.76668 & 0.7663 & 0.76368 & 0.75805 & 0.73663 \\
Black & 0.66095 & 0.69641 & 0.67158 & 0.66007 & 0.67315 & 0.66632 & 0.67205 \\
Hispanic & 0.6985 & 0.708 & 0.70102 & 0.70944 & 0.72498 & 0.70328 & 0.69463 \\
Asian & 0.70391 & 0.72741 & 0.71571 & 0.7275 & 0.73717 & 0.73004 & 0.71009 \\
Mixed & 0.69103 & 0.71635 & 0.69882 & 0.69746 & 0.69956 & 0.6924 & 0.68355
\end{tabular}

C

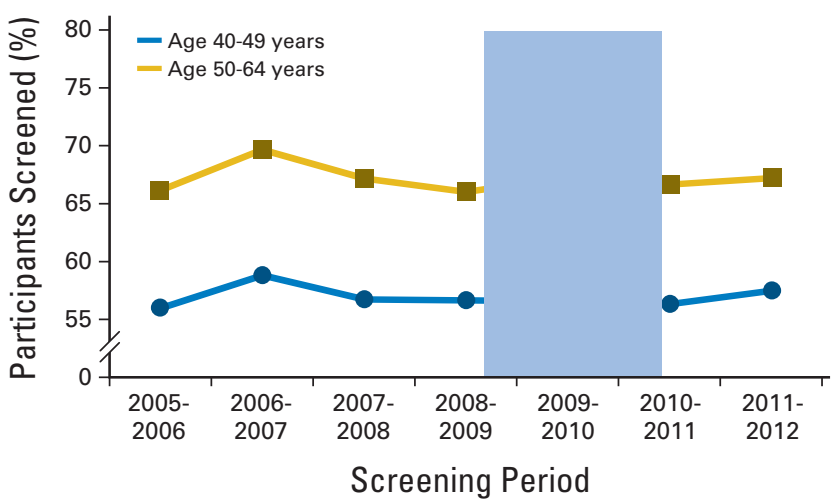

E

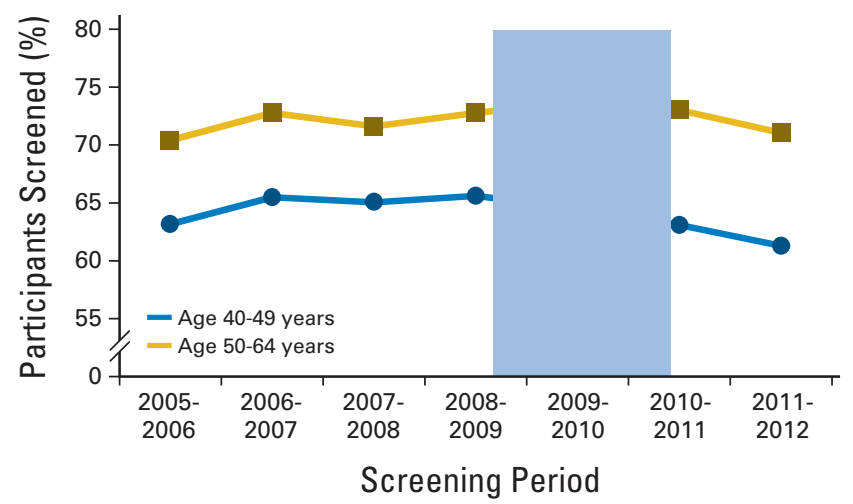

D

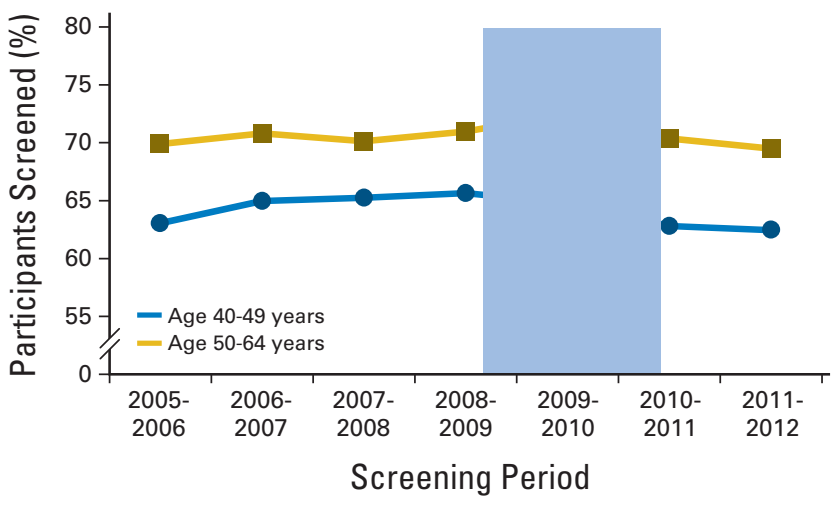

$\mathbf{F}$

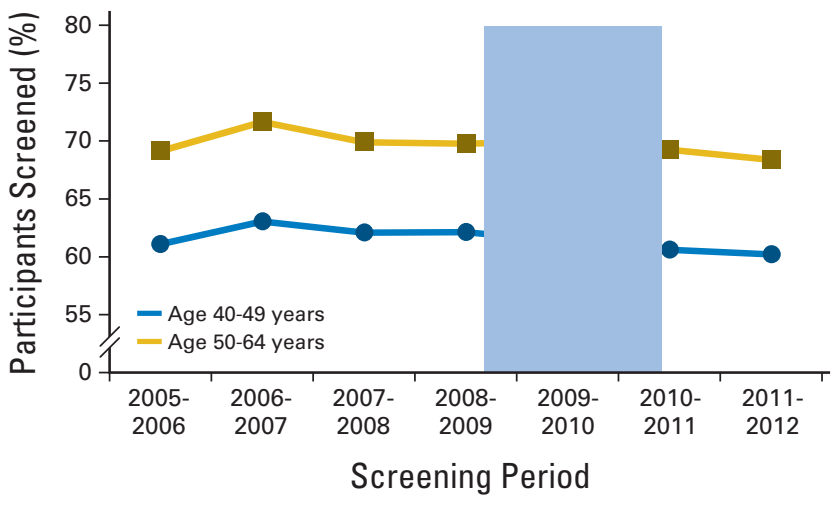

Fig 2. Adjusted biennial mammography rates before and after the November 2009 US Preventive Services Task Force breast cancer screening guideline changes:

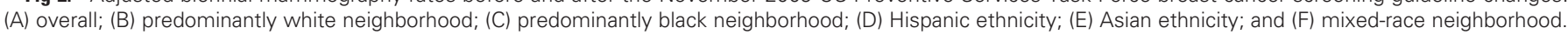




\begin{tabular}{|c|c|c|c|c|c|c|c|c|}
\hline \multirow[b]{2}{*}{ Age and Race } & \multicolumn{2}{|c|}{$\begin{array}{c}\text { Estimated* } \\
2012 \text { Rate (\%) }\end{array}$} & \multicolumn{2}{|c|}{$\begin{array}{c}\text { Predicted } \\
2012 \text { Rate (\%) }\end{array}$} & \multicolumn{2}{|c|}{$\begin{array}{l}\text { Estimated* Absolute } \\
\text { Difference Between Predicted } \\
\text { and Observed } 2012 \text { Rate (\%) }\end{array}$} & \multicolumn{2}{|c|}{$\begin{array}{c}\text { Estimated } \neq \text { Relative Difference } \\
\text { Between Predicted and } \\
\text { Observed } 2012 \text { Rate (\%) }\end{array}$} \\
\hline & Rate & $95 \% \mathrm{Cl}$ & Rate & $95 \% \mathrm{Cl}$ & Difference & $95 \% \mathrm{Cl}$ & Difference & $95 \% \mathrm{Cl}$ \\
\hline \multicolumn{9}{|l|}{ Annual } \\
\hline Age $40-49$ years & 38.8 & 38.6 to 39.0 & 43.1 & 43.1 to 43.2 & -4.3 & -4.6 to -4.1 & -9.9 & -10.4 to -9.3 \\
\hline White & 40.4 & 40.2 to 40.7 & 44.8 & 44.7 to 44.8 & -4.3 & -4.6 to -4.0 & -9.4 & -10.1 to -8.8 \\
\hline Black & 34.2 & 33.0 to 35.4 & 35.2 & 34.8 to 35.6 & -1.0 & -2.3 to 0.4 & -2.3 & -6.3 to 1.8 \\
\hline Hispanic & 35.4 & 34.8 to 36.0 & 41.3 & 41.0 to 41.5 & -5.9 & -6.6 to -5.2 & -14.2 & -15.9 to -12.5 \\
\hline Asian & 34.7 & 33.8 to 35.6 & 41.9 & 41.5 to 42.3 & -7.2 & -8.3 to -6.1 & -17.4 & -20.0 to -14.8 \\
\hline Mixed & 35.6 & 35.1 to 36.1 & 38.8 & 38.6 to 39.0 & -3.2 & -3.8 to -2.7 & -8.1 & -9.6 to -6.6 \\
\hline Age 50-64 years & 47.5 & 47.3 to 47.7 & 50.7 & 50.6 to 50.8 & -3.3 & -3.5 to -3.0 & -6.1 & -6.5 to -5.7 \\
\hline White & 49.0 & 48.8 to 49.2 & 52.3 & 52.2 to 52.4 & -3.3 & -3.6 to -3.1 & -6.0 & -6.5 to -5.6 \\
\hline Black & 43.9 & 42.8 to 44.9 & 44.0 & 43.6 to 44.5 & -0.2 & -1.4 to 1.0 & 0.9 & -1.9 to 3.8 \\
\hline Hispanic & 43.2 & 42.6 to 43.9 & 47.0 & 46.7 to 47.3 & -3.8 & -4.6 to -3.0 & -7.6 & -9.2 to -5.8 \\
\hline Asian & 43.4 & 42.4 to 44.5 & 49.0 & 48.5 to 49.5 & -5.6 & -6.9 to -4.3 & -11.4 & -14.0 to -8.7 \\
\hline Mixed & 43.3 & 42.8 to 43.7 & 46.3 & 46.2 to 46.5 & -3.1 & -3.6 to -2.5 & -6.2 & -7.4 to -5.1 \\
\hline \multicolumn{9}{|l|}{ Biennial } \\
\hline Age $40-49$ years & 65.8 & 65.4 to 66.1 & 71.9 & 71.8 to 72.1 & -6.2 & -6.6 to -5.7 & -9.0 & -9.6 to -8.4 \\
\hline White & 67.4 & 67.0 to 67.9 & 74.4 & 74.2 to 74.6 & -7.0 & -7.5 to -6.4 & -9.8 & -10.5 to -9.2 \\
\hline Black & 58.9 & 56.8 to 61.1 & 59.0 & 58.2 to 59.7 & 0.0 & -2.5 to 2.5 & 0.1 & -4.0 to 4.3 \\
\hline Hispanic & 62.8 & 61.6 to 63.9 & 68.8 & 68.3 to 69.2 & -6.0 & -7.4 to -4.6 & -9.2 & -11.0 to -7.2 \\
\hline Asian & 62.3 & 60.5 to 64.1 & 69.4 & 68.6 to 70.1 & -7.1 & -9.3 to -4.9 & -10.6 & -13.6 to -7.5 \\
\hline Mixed & 61.7 & 60.7 to 62.6 & 65.6 & 65.2 to 65.9 & -3.9 & -5.0 to -2.8 & -6.2 & -7.8 to -4.5 \\
\hline Age $50-64$ years & 76.5 & 76.1 to 76.8 & 81.2 & 81.0 to 81.3 & -4.7 & -5.1 to -4.3 & -6.2 & -6.6 to -5.7 \\
\hline White & 78.0 & 77.6 to 78.4 & 83.4 & 83.3 to 83.6 & -5.4 & -5.9 to -5.0 & -7.0 & -7.5 to -6.4 \\
\hline Black & 71.0 & 69.2 to 72.8 & 71.3 & 70.6 to 72.1 & -0.4 & -2.5 to 1.8 & 0.4 & -2.6 to 3.5 \\
\hline Hispanic & 72.1 & 70.9 to 73.2 & 76.0 & 75.5 to 76.5 & -3.9 & -5.4 to -2.5 & -5.7 & -7.6 to -3.8 \\
\hline Asian & 72.8 & 70.9 to 74.8 & 78.3 & 77.4 to 79.1 & -5.5 & -7.9 to -3.0 & -7.4 & -10.4 to -4.4 \\
\hline Mixed & 72.7 & 71.8 to 73.5 & 75.1 & 74.7 to 75.4 & -2.4 & -3.4 to -1.4 & -3.3 & -4.6 to -1.9 \\
\hline
\end{tabular}

group. In addition, the USPSTF recommended that women in this age group make personalized decisions with their health care providers; black women, who have the highest risk of breast cancer mortality, ${ }^{44}$ showed lesser reductions in mammography compared with women at lower risk.

Nevertheless, our study is unable to determine exact reasons for the patterns we detected, and it is likely that factors such as racial attitudes about cancer screening, ${ }^{45}$ trust in consensus guidelines, previously established screening patterns, ${ }^{46,47}$ physician financial incentives, ${ }^{48,49}$ and willingness to change preventive care patterns mitigated or reinforced USPSTF recommendations after 2009.

The USPSTF guidelines are highly controversial, and it is informative to interpret results from the perspective of both USPSTF proponents and those who favor a more intense screening approach. Proponents are likely to consider decreases in screening among women age 40 to 49 years to be appropriate, or perhaps even too small, given studies suggesting population-level harms in this age group such as false-positive tests and unnecessary surgery. ${ }^{15-18}$ These proponents might also be reassured that reductions in biennial screening among women age 50 to 64 years were not large but be concerned that the reduced rates after 2009 might represent an unintended consequence that could jeopardize Healthy People 2020 mammography goals. ${ }^{50}$
Advocates of a more intense breast cancer screening approach, as reflected in other consensus guidelines, ${ }^{20-24}$ are likely to consider all screening reductions concerning. These advocates might consider that decades of progress in increasing screening may have been reversed.

Our findings demonstrating small to moderate decreases in mammography after 2009 are consistent with two smaller shorterterm studies that also used administrative data. Sharpe et $\mathrm{al}^{34}$ studied older women using Medicare part B data and found a 4.3\% decline in 2010 mammography versus 2009 mammography rates. A study using a Vermont mammography registry also found a larger reduction among women age 40 to 49 years $(4.8 \%)$ than women age 50 to 74 years $(3.0 \%) .^{33} \mathrm{~A}$ third study using health insurance claims data found slight trend increases in monthly mammography after the USPSTF guideline changes ${ }^{51}$ but used a more restrictive definition of breast cancer screening that used only tests coded as screening mammograms. As mentioned earlier, we intentionally included both screening and diagnostic mammograms to provide a broad measure of population screening rates given that women are considered screened for breast cancer if they receive either a screening or diagnostic mammogram. Two studies using self-reported data found no change in mammography after 2009. Pace et $\mathrm{al}^{32}$ found that mammography rates between 2008 
and 2011 were unchanged in the 40- to 49-year and 50- to 74-year age groups. Similarly, Howard and Adams ${ }^{31}$ detected no change between 2010 and earlier years. It is possible that the substantial media attention to and criticisms of the USPSTF guideline changes ${ }^{27-30}$ might have differentially changed response or recall bias over time. Investigators have previously found that selfreported data overestimate cancer screening. ${ }^{52}$

We believe that our study, comprising more than 2 million women per year, provides results generalizable to commercially insured women. The insurer whose data we studied contractually requires that all claims be submitted, so we likely have a precise estimate of screening rates. Our large sample size allowed us to generate additional insights by stratifying both by age group and race/ethnicity, demonstrating, for example, potential differential responsiveness to the guidelines.

Our study has four main limitations. We assumed that the increases in screening from 2005 to 2009 were linear and would have continued at the same rate until 2012 in the absence of the USPSTF guidelines. We cannot rule out the possibility of a nonlinear trend or other factors that could have influenced screening patterns after 2009. However, our finding of a decrease in rates immediately after publication of the USPSTF guidelines and concomitant major media coverage provides strong evidence of a causal link. ${ }^{53}$ Furthermore, only examining rates before and after the guidelines change amounts to an uncontrolled pre-post design, which is invalid for causal inference. ${ }^{53,54}$ The Cochran group ${ }^{54}$ and Shadish et $\mathrm{al}^{53}$ recognize interrupted time series design, the approach we used, as the strongest quasi-experimental design that controls for most common threats to validity (except co-interventions). In addition, the assumption of a nonlinear flattening of trend after 2009 is also an assumption and one that might have less support given historically increasing trends in breast cancer screening. Furthermore, even presuming a flattened trend after 2009, we detected statistically significant reductions among all nonblack women, although such decreases were attenuated. The latter approach provides perhaps a lower bound on the impact of the 2009 USPSTF guidelines change. However, using a screening-specific mammography measure, we detected larger reductions after the USPSTF guideline changes (Appendix Table A4), which might represent an upper bound of impacts. Given that the overwhelming majority of diagnostic and screening mammograms ultimately do not lead to a breast cancer diagnosis, women undergoing either test type are effectively screened for the subsequent 1 or 2 years. As a result and because providers might not code screening mammograms correctly (especially after a policy change that might reduce revenue), ${ }^{43}$ we believe that our primary mammography measure, which included any mammogram and is consistent with the well-established Healthcare Effectiveness Data and Information Set measure, ${ }^{36}$ is most appropri- ate, while also leading to a more conservative estimate of the USPSTF guidelines effect compared with a screening-specific measure. Although our results should be generalizable to the commercially insured population under age 65 years given the large size of the insurer whose data we examined, this data set is associated with several limitations. We were unable to assess physician-level interventions and reimbursement rates unique to the health insurer, but it is unlikely that these differed substantially from secular patterns or that providers would be highly aware of the specific health insurer of their patients or details of how that health insurer reimburses differentially from other private health insurers. Our results may not represent patterns in populations such as the uninsured or those covered by Medicaid. Finally, our measures of race/ethnicity were not based on self-report, the gold standard, but rather on surname analysis and geocoded data. However, this classification approach has positive and negative predictive values of approximately $80 \%$ and $90 \%$, respectively. ${ }^{38}$

In conclusion, we found that mammography decreased among nonblack women after 2009 and in a manner mostly consistent with updated USPSTF mammography guidelines. For proponents of the guidelines, our findings imply some degree of success in promulgation of the recommendations but a need to promote biennial mammography to avoid downward trends.

Those who favor a more intense screening approach should work to promote screening in all age and demographic groups, perhaps focusing more on younger Hispanic and Asian women who experienced the largest decreases. A key future research priority will be to examine potential benefits (such as fewer false-positive tests and unnecessary surgeries) and unintended consequences (such as reduced biennial screening rates and increased breast cancer death) of the guideline changes.

\section{AUTHORS' DISCLOSURES OF POTENTIAL CONFLICTS} OF INTEREST

Disclosures provided by the authors are available with this article at www.jco.org.

\section{AUTHOR CONTRIBUTIONS}

Conception and design: J. Frank Wharam, Bruce Landon, Fang Zhang, Stephen Soumerai, Dennis Ross-Degnan

Collection and assembly of data: J. Frank Wharam

Data analysis and interpretation: All authors

Manuscript writing: All authors

Final approval of manuscript: All authors

\section{REFERENCES}

1. Centers for Disease Control and Prevention: 2006-2010 top ten cancers. National Program of Cancer Registries 2014. http://apps.nccd.cdc.gov/ uscs/toptencancers.aspx

2. Tabar L, Fagerberg CJ, Gad A, et al: Reduction in mortality from breast cancer after mass screening with mammography: Randomised trial from the Breast Cancer Screening Working Group of the Swedish National Board of Health and Welfare. Lancet 1:829-832, 1985
3. Roberts MM, Alexander FE, Anderson TJ, et al: Edinburgh trial of screening for breast cancer: Mortality at seven years. Lancet 335:241-246, 1990

4. Andersson I, Aspegren K, Janzon L, et al: Mammographic screening and mortality from breast cancer: The Malmo mammographic screening trial. BMJ 297:943-948, 1988

5. Cronin KA, Feuer EJ, Clarke LD, et al: Impact of adjuvant therapy and mammography on U.S. mortality from 1975 to 2000: Comparison of mortality results from the cisnet breast cancer base case analysis. J Natl Cancer Inst Monogr 36:112-121, 2006
6. Berry DA, Cronin KA, Plevritis SK, et al: Effect of screening and adjuvant therapy on mortality from breast cancer. N Engl J Med 353:1784-1792, 2005

7. Christensen LH, Engholm G, Cortes R, et al: Reduced mortality for women with mammographydetected breast cancer in east Denmark and south Sweden. Eur J Cancer 42:2773-2780, 2006

8. Hershman DL, Shao T, Kushi LH, et al: Early discontinuation and non-adherence to adjuvant hormonal therapy are associated with increased mortality in women with breast cancer. Breast Cancer Res Treat 126:529-537, 2011 
9. Laara E, Day NE, Hakama M: Trends in mortality from cervical cancer in the Nordic countries: Association with organised screening programmes. Lancet 1:1247-1249, 1987

10. Eddy DM: Screening for cervical cancer. Ann Intern Med 113:214-226, 1990

11. Gotzsche PC, Jorgensen KJ: Screening for breast cancer with mammography. Cochrane Database Syst Rev 6:CD001877, 2013

12. Miller AB, Wall $C$, Baines $C J$, et al: Twenty five year follow-up for breast cancer incidence and mortality of the Canadian National Breast Screening Study: Randomised screening trial. BMJ 348:g366, 2014

13. Hendrick RE, Helvie MA: United States Preventive Services Task Force screening mammography recommendations: Science ignored. AJR Am J Roentgenol 196:W112-W116, 2011

14. Kopans DB: The 2009 US Preventive Services Task Force (USPSTF) guidelines are not supported by science: The scientific support for mammography screening. Radiol Clin North Am 48:843-857, 2010

15. Screening for breast cancer: U.S. Preventive Services Task Force recommendation statement. Ann Intern Med 151:716-726, 2009

16. Bleyer A, Welch HG: Effect of three decades of screening mammography on breast-cancer incidence. N Engl J Med 367:1998-2005, 2012

17. Kalager $M$, Adami $H O$, Bretthauer $M$, et al: Overdiagnosis of invasive breast cancer due to mammography screening: Results from the Norwegian screening program. Ann Intern Med 156:491-499, 2012

18. Gross CP, Long JB, Ross JS, et al: The cost of breast cancer screening in the Medicare population. JAMA Intern Med 173:220-226, 2013

19. US Preventive Services Taskforce: Screening for breast cancer: Recommendations and rationale. Ann Intern Med 137:344-346, 2002

20. Bevers TB, Anderson BO, Bonaccio E, et al: NCCN clinical practice guidelines in oncology Breast cancer screening and diagnosis. J Natl Compr Canc Netw 7:1060-1096, 2009

21. Smith RA, Saslow D, Sawyer KA, et al: American Cancer Society guidelines for breast cancer screening: Update 2003. CA Cancer J Clin 53:141169, 2003

22. American College of Obstetricians-Gynecologists: Practice bulletin no. 122: Breast cancer screening. Obstet Gynecol 118:372-382, 2011

23. American Medical Association: AMA adopts new policies at annual meeting. 2012. http://www.amaassn.org/ama/pub/news/news/2012-06-19-ama-adoptsnew-policies.page

24. American College of Radiology: ACR Appropriateness Criteria ${ }^{\circledR}$ breast cancer screening. http:// www.acr.org/ /media/ACR/Documents/AppCriteria/ Diagnostic/BreastCancerScreening.pdf
25. Association of European Cancer Leagues: EU Council Recommendation on Cancer Screening. http:// www.europeancancerleagues.org/cancer-in-europe/ resources-on-cancer-in-europe/82-eu-councilrecommendation-on-cancer-screening.htm

26. Canadian Task Force on Preventive Health Care: Screening for breast cancer: Summary of recommendations for clinicians and policy-makers. http:// canadiantaskforce.ca/guidelines/2011-breast-cancer/

27. Kolata G: Panel urges mammograms at 50 , not 40. New York Times, 2009. http://www.nytimes.com/ 2009/11/17/health/17cancer.html?_r=0

28. Stein R: Federal panel recommends reducing number of mammograms. Washington Post, 2009. http://www.washingtonpost.com/wp-dyn/content/ article/2009/11/16/AR2009111602822.html

29. Wang SS: Breast-screening advice is upended. Wall Street Journal, 2009. http://online.wsj.com/news/ articles/SB100014240527487045384045745399 71868397840

30. Dellorto D: Task force opposes routine mammograms for women age 40-49. http://www.cnn.com/ 2009/HEALTH/11/16/mammography.recommendation changes/index.html?eref $=$ rss_latest

31. Howard DH, Adams EK: Mammography rates after the 2009 US Preventive Services Task Force breast cancer screening recommendation. Prev Med 55:485-487, 2012

32. Pace LE, He Y, Keating NL: Trends in mammography screening rates after publication of the 2009 US Preventive Services Task Force recommendations. Cancer 119:2518-2523, 2013

33. Sprague BL, Bolton $\mathrm{KC}$, Mace JL, et al: Registry-based Study of trends in breast cancer screening mammography before and after the 2009 U.S. Preventive Services Task Force recommendations. Radiology 270:354-361, 2014

34. Sharpe RE Jr, Levin DC, Parker L, et al: The effect of the controversial US Preventive Services Task Force recommendations on the use of screening mammography. J Am Coll Radiol 10:21-24, 2013

35. Optum: Clinformatics Data Mart. http:// www.optum.com/content/dam/optum/resources/ productSheets/Clinformatics-Data-Mart.pdf

36. National Committee for Quality Assurance: HEDIS ${ }^{\circledR}$ 2014: Healthcare Effectiveness Data and Information Set. http://www.ncqa.org/Portals/0/HEDISQM/ HEDIS2014/List_of_HEDIS_2014_Measures.pd

37. Ethnic Technologies: Homepage. http://www ethnictechnologies.com

38. Fiscella K, Fremont AM: Use of geocoding and surname analysis to estimate race and ethnicity. Health Serv Res 41:1482-1500, 2006

39. Krieger N, Chen JT, Waterman PD, et al: Race/ethnicity, gender, and monitoring socioeconomic gradients in health: A comparison of areabased socioeconomic measures-The public health disparities geocoding project. Am J Public Health 93:1655-1671, 2003

40. Liang KY, Zeger SL: Longitudinal data analysis using generalized linear models. Biometrika 73:1322, 1986

41. Zeger SL, Liang KY: Longitudinal data analysis for discrete and continuous outcomes. Biometrics 42:121-130, 1986

42. Li Z, Mahendra G: SAS Global Forum 2010. http:// support.sas.com/resources/papers/proceedings10/2722010.pdf.

43. Fenton JJ, Zhu W, Balch S, et al: Distinguishing screening from diagnostic mammograms using Medicare claims data. Med Care 52:e44-e51, 2014

44. National Cancer Institute: Surveillance, Epidemiology, and End Results: Fast stats: Age-adjusted rates by data type female breast, ages 50-64, 1992-2010. http:// seer.cancer.gov/faststats/selections.php?\#Output

45. Miller AM, Champion VL: Attitudes about breast cancer and mammography: Racial, income, and educational differences. Women Health 26:4163, 1997

46. Breen N, Gentleman JF, Schiller JS: Update on mammography trends: Comparisons of rates in 2000, 2005, and 2008. Cancer 117:2209-2218, 2011

47. Zhou J, Enewold L, Peoples GE, et al: Trends in cancer screening among Hispanic and white nonHispanic women, 2000-2005. J Womens Health (Larchmt) 19:2167-2174, 2010

48. National Committee for Quality Assurance: HEDIS 2013. http://www.ncqa.org/HEDISQualityMeasurement/ HEDISMeasures/HEDIS2013.aspx

49. Centers for Medicare and Medicaid Services: Accountable Care Organization 2013 Program Analysis: Quality Performance Standards Narrative Measure Specifications. http://www.michiganpioneeraco.com/upload/ docs/2013-ACO-NarrativeMeasureSpecs.pdf

50. US Department of Health and Human Services: Healthy People 2020. http://www.healthy people.gov/2020/topicsobjectives2020/default.aspx

51. Wang AT, Fan J, Van Houten HK, et al: Impact of the 2009 US Preventive Services Task Force guidelines on screening mammography rates on women in their 40s. PLoS One 9:e91399, 2014

52. Njai R, Siegel PZ, Miller JW, et al: Misclassification of survey responses and black-white disparity in mammography use, Behavioral Risk Factor Surveillance System, 1995-2006. Prev Chronic Dis 8:A59, 2011

53. Shadish WR, Cook TD, Campbell DT: Experimental and Quasi-Experimental Designs for Generalized Causal Inference. Boston, MA, Houghton Mifflin, 2001

54. Higgins JPT, Green S, Cochrane Collaboration: Cochrane Handbook for Systematic Reviews of Interventions. Hoboken, NJ, Wiley-Blackwell, 2008 


\section{AUTHORS' DISCLOSURES OF POTENTIAL CONFLICTS OF INTEREST}

Mammography Rates 3 Years After the 2009 US Preventive Services Task Force Guidelines Changes

The following represents disclosure information provided by authors of this manuscript. All relationships are considered compensated. Relationships are self-held unless noted. I = Immediate Family Member, Inst = My Institution. Relationships may not relate to the subject matter of this manuscript. For more information about ASCO's conflict of interest policy, please refer to www.asco.org/rwc or jco.ascopubs.org/site/ifc.

\section{J. Frank Wharam}

No relationship to disclose

Bruce Landon

Stock or Other Ownership: Activate Networks

Honoraria: Pfizer

Consulting or Advisory Role: Evidera/Merck

Patents, Royalties, Other Intellectual Property: Activate Networks

Travel, Accommodations, Expenses: Pfizer

Fang Zhang

Consulting or Advisory Role: Policy Analysis

\section{$\mathrm{Xin} \mathrm{Xu}$}

No relationship to disclose

\section{Stephen Soumerai}

No relationship to disclose

\section{Dennis Ross-Degnan}

No relationship to disclose 


\section{Acknowledgment}

We acknowledge the helpful comments of Suzanne W. Fletcher, MD, MSc, Professor Emeritus, Department of Population Medicine, Harvard Medical School and Harvard Pilgrim Health Care Institute (Boston, MA).

\section{Appendix}

\section{Regression Model for Our Annual and Biennial Analyses}

- Regression type: generalized estimating equations regression, person-level with one record per person-time interval

- Distribution: Poisson

- Clustering variable: subject ID

- Type: first-order autoregressive

- Regression model: Mammography rate $=\beta 0+\beta 1^{\star}$ calendar_year_period $+\beta 2^{\star} 2012 / 2011-12 \_$period $+\beta 3^{\star}$ age + $\beta 4^{\star}$ region_dummies $+\beta 5^{\star}$ education_level_dummies $+\beta 6^{\star}$ poverty_level_dummies $+\beta 7^{\star}$ race_category_dummies

\section{Example of Numerator and Denominator Construction}

For our annual outcome, a woman who was continuously enrolled from January 1, 2005, until December 31, 2012, would initially contribute eight records for each of the calendar years of 2005, 2006, 2007, 2008, 2009, 2010, 2011, and 2012, although 2010 and 2011 are ultimately excluded because we estimate the difference between 2012 expected and actual rates. This same woman would contribute seven records for the biennial outcome (2005 to 2006, 2006 to 2007, 2007 to 2008, 2008 to 2009, 2009 to 2010, 2010 to 2011, and 2011 to 2012, although 2009 to 2010 and 2010 to 2011 are ultimately excluded. For the biennial outcome, if a woman was screened twice (or more) in the given 2-year period, that would still only count as a 1 in the numerator. The same holds for the annual outcome, where the outcome for a given woman was binary no matter how many mammographies occurred in the 1-year period of interest.

\begin{tabular}{|c|c|c|c|c|}
\hline Code Type & CPT Codes & HCPCS Codes & $\begin{array}{l}\text { ICD-9 Diagnosis } \\
\text { Codes }\end{array}$ & ICD-9 Procedure Codes \\
\hline $\begin{array}{l}\text { Codes used to create } \\
\text { numerator } \\
\text { mammography } \\
\text { event }\end{array}$ & $\begin{array}{c}76083,76090,76091,76092 \\
77055,77056,77057\end{array}$ & $\begin{array}{l}\text { G0202, G0203, G0204, } \\
\text { G0205, G0206 }\end{array}$ & $\begin{array}{l}\text { V7611, V7612, } \\
\text { V761, V7610, } \\
\text { V7619 }\end{array}$ & \\
\hline $\begin{array}{l}\text { Codes used to } \\
\text { exclude women } \\
\text { from the } \\
\text { denominator }\end{array}$ & $\begin{array}{l}\text { 19180, 19200, 19220, 19240, } \\
\text { 19303, 19304, 19305, } \\
\text { 19306, } 19307\end{array}$ & $\begin{array}{l}\text { L8600, L8000, L8010, L8020, } \\
\text { L8030, L8001, L8002, } \\
\text { L8015, L8035, L8039 }\end{array}$ & & $\begin{array}{l}8541,8542,8543,8544, \\
8545,8546,8547, \\
8548\end{array}$ \\
\hline
\end{tabular}

\begin{tabular}{|c|c|c|c|c|}
\hline \multicolumn{5}{|c|}{$\begin{array}{c}\text { Table A2. Relative Level and Trend Changes in Quarterly Mammography Rates From Before to After the } 2009 \text { US Preventive Services Task Force } \\
\text { Mammography Guidelines Change }\end{array}$} \\
\hline \multirow[b]{2}{*}{ Age and Race } & \multicolumn{2}{|c|}{ Relative Level Change* (\%) } & \multicolumn{2}{|c|}{ Relative Trend Change† (\%) } \\
\hline & Rate & $95 \% \mathrm{Cl}$ & Rate & $95 \% \mathrm{Cl}$ \\
\hline Age $40-49$ years & -6.46 & -6.83 to -6.09 & 0.24 & 0.19 to 0.29 \\
\hline White & -6.24 & -6.67 to -5.80 & 0.23 & 0.17 to 0.29 \\
\hline Black & -6.58 & -9.04 to -4.06 & 1.13 & 0.78 to 1.48 \\
\hline Hispanic & -9.53 & -10.71 to -8.33 & 0.20 & 0.03 to 0.37 \\
\hline Asian & -6.00 & -7.86 to -4.10 & -0.53 & -0.79 to -0.27 \\
\hline Mixed & -5.56 & -6.57 to -4.53 & 0.35 & 0.21 to 0.49 \\
\hline Age 50-64 years & -2.07 & -2.35 to -1.79 & -0.01 & -0.05 to 0.03 \\
\hline White & -2.01 & -2.34 to -1.69 & -0.04 & -0.09 to 0.00 \\
\hline Black & -0.74 & -2.48 to 1.03 & 0.71 & 0.48 to 0.95 \\
\hline Hispanic & -3.62 & -4.75 to -2.49 & 0.10 & -0.05 to 0.25 \\
\hline Asian & -1.65 & -3.44 to 0.17 & -0.45 & -0.68 to -0.21 \\
\hline Mixed & -1.87 & -2.64 to -1.10 & 0.02 & -0.08 to 0.12 \\
\hline
\end{tabular}




\begin{tabular}{|c|c|c|c|c|c|c|c|c|}
\hline \multirow[b]{2}{*}{ Age and Race } & \multicolumn{2}{|c|}{$\begin{array}{c}\text { Estimated* } \\
2009 \text { Rate (\%) }\end{array}$} & \multicolumn{2}{|c|}{$\begin{array}{c}\text { Estimated* } \\
2012 \text { Rate (\%) }\end{array}$} & \multicolumn{2}{|c|}{$\begin{array}{c}\text { Estimated* Absolute } \\
\text { Difference Between } 2009 \text { and } \\
2012 \text { Rate (\%) }\end{array}$} & \multicolumn{2}{|c|}{$\begin{array}{c}\text { Estimatedt Relative Difference } \\
\text { Between } 2009 \text { and } 2012 \\
\text { Rate (\%) }\end{array}$} \\
\hline & Rate & $95 \% \mathrm{Cl}$ & Rate & $95 \% \mathrm{Cl}$ & Difference & $95 \% \mathrm{Cl}$ & Difference & $95 \% \mathrm{Cl}$ \\
\hline \multicolumn{9}{|l|}{$\overline{\text { Annual }}$} \\
\hline Age $40-49$ years & 42.9 & 42.8 to 43.0 & 40.1 & 40.0 to 40.3 & -2.8 & -2.9 to -2.7 & -4.5 & -4.9 to -4.2 \\
\hline White & 44.5 & 44.4 to 44.6 & 41.7 & 41.5 to 41.9 & -2.8 & -2.9 to -2.7 & -4.5 & -4.9 to -4.1 \\
\hline Black & 34.9 & 34.5 to 35.3 & 35.7 & 34.7 to 36.7 & 0.8 & 0.2 to 1.4 & 5.0 & 2.2 to 7.8 \\
\hline Hispanic & 40.9 & 40.6 to 41.1 & 37.1 & 36.6 to 37.6 & -3.7 & -4.0 to -3.5 & -6.7 & -7.9 to -5.5 \\
\hline Asian & 41.5 & 41.1 to 41.8 & 36.1 & 35.4 to 36.8 & -5.3 & -5.6 to -5.0 & -11.0 & -12.7 to -9.2 \\
\hline Mixed & 38.6 & 38.4 to 38.7 & 36.8 & 36.4 to 37.2 & -1.7 & -1.9 to -1.5 & -2.4 & -3.4 to -1.3 \\
\hline Age 50-64 years & 50.5 & 50.5 to 50.6 & 48.4 & 48.2 to 48.5 & -2.1 & -2.2 to -2.1 & -2.9 & -3.2 to -2.6 \\
\hline White & 52.2 & 52.1 to 52.2 & 49.8 & 49.7 to 50.0 & -2.3 & -2.4 to -2.2 & -3.2 & -3.5 to -2.9 \\
\hline Black & 43.8 & 43.4 to 44.2 & 45.0 & 44.2 to 45.8 & 1.2 & 0.8 to 1.6 & 5.0 & 3.2 to 6.9 \\
\hline Hispanic & 46.7 & 46.4 to 47.0 & 44.6 & 44.1 to 45.1 & -2.1 & -2.4 to -1.9 & -2.8 & -3.9 to -1.6 \\
\hline Asian & 48.5 & 48.0 to 48.9 & 45.3 & 44.5 to 46.1 & -3.2 & -3.5 to -2.8 & -4.2 & -6.0 to -2.4 \\
\hline Mixed & 46.1 & 45.9 to 46.3 & 44.3 & 43.9 to 44.6 & -1.9 & -2.0 to -1.7 & -2.3 & -3.1 to -1.5 \\
\hline \multicolumn{9}{|l|}{ Biennial } \\
\hline Age $40-49$ years & 71.8 & 71.7 to 71.9 & 66.5 & 66.3 to 66.8 & -5.3 & -5.4 to -5.1 & -7.2 & -7.5 to -6.8 \\
\hline White & 74.3 & 74.1 to 74.4 & 68.2 & 67.9 to 68.6 & -6.0 & -6.2 to -5.8 & -8.0 & -8.4 to -7.5 \\
\hline Black & 58.9 & 58.2 to 59.7 & 59.0 & 57.5 to 60.5 & 0.1 & -0.7 to 0.9 & 0.2 & -2.2 to 2.6 \\
\hline Hispanic & 68.4 & 68.0 to 68.8 & 64.2 & 63.4 to 65.0 & -4.2 & -4.7 to -3.8 & -5.5 & -6.7 to -4.3 \\
\hline Asian & 69.1 & 68.4 to 69.7 & 63.5 & 62.2 to 64.7 & -5.6 & -6.2 to -5.0 & -7.7 & -9.5 to -5.9 \\
\hline Mixed & 65.5 & 65.2 to 65.8 & 62.1 & 61.5 to 62.8 & -3.4 & -3.7 to -3.0 & -5.2 & -6.1 to -4.2 \\
\hline Age $50-64$ years & 81.1 & 81.0 to 81.2 & 76.6 & 76.4 to 76.9 & -4.5 & -4.6 to -4.4 & -5.9 & -6.2 to -5.6 \\
\hline White & 83.4 & 83.2 to 83.5 & 78.2 & 77.9 to 78.4 & -5.2 & -5.3 to -5.1 & -6.7 & -7.0 to -6.4 \\
\hline Black & 71.5 & 70.8 to 72.1 & 70.5 & 69.2 to 71.7 & -1.0 & -1.6 to -0.4 & -1.8 & -3.5 to -0.1 \\
\hline Hispanic & 75.7 & 75.2 to 76.1 & 73.2 & 72.3 to 74.0 & -2.5 & -2.9 to -2.1 & -3.3 & -4.4 to -2.1 \\
\hline Asian & 77.9 & 77.1 to 78.6 & 74.3 & 72.9 to 75.6 & -3.6 & -4.2 to -3.0 & -4.3 & -6.1 to -2.6 \\
\hline Mixed & 75.1 & 74.8 to 75.4 & 72.4 & 71.8 to 73.0 & -2.7 & -3.0 to -2.4 & -4.0 & -4.8 to -3.3 \\
\hline
\end{tabular}


Table A4. Estimated Relative Change in Annual and Biennial Mammography Rates Before and After the 2009 US Preventive Services Task Force Guideline Changes, Using a Screening-Specific Mammography Measure

\begin{tabular}{|c|c|c|c|c|}
\hline \multirow[b]{2}{*}{ Age and Race } & \multicolumn{2}{|c|}{$\begin{array}{c}\text { Relative Change, Presuming Flattening of } \\
\text { Trend After } 2009^{*}(\%)\end{array}$} & \multicolumn{2}{|c|}{$\begin{array}{c}\text { Relative Change, Presuming a Continuation of } \\
\text { 2005-2009 Trends After 2009* }(\%)\end{array}$} \\
\hline & Rate & $95 \% \mathrm{Cl}$ & Rate & $95 \% \mathrm{Cl}$ \\
\hline \multicolumn{5}{|l|}{ Annual } \\
\hline Age $40-49$ years & -8.7 & -9.0 to -8.3 & -19.1 & -19.6 to -18.6 \\
\hline White & -8.6 & -9.1 to -8.2 & -18.4 & -19.0 to -17.8 \\
\hline Black & 0.6 & -2.2 to 3.5 & -12.9 & -16.6 to -9.1 \\
\hline Hispanic & -11.2 & -12.4 to -10.0 & -25.1 & -26.7 to -23.5 \\
\hline Asian & -14.2 & -16.0 to -12.4 & -24.7 & -27.2 to -22.2 \\
\hline Mixed & -6.7 & -7.8 to -5.6 & -18.0 & -19.4 to -16.6 \\
\hline Age $50-64$ years & -6.7 & -7.8 to -5.6 & -18.0 & -19.4 to -16.6 \\
\hline White & -6.4 & -6.7 to -6.0 & -14.1 & -14.6 to -13.6 \\
\hline Black & 1.1 & -0.8 to 3.0 & -8.5 & -11.2 to -5.8 \\
\hline Hispanic & -6.7 & -7.9 to -5.5 & -18.5 & -20.0 to -16.8 \\
\hline Asian & -7.5 & -9.3 to -5.7 & -19.3 & -21.8 to -16.7 \\
\hline Mixed & -5.5 & -6.3 to -4.7 & -14.3 & -15.5 to -13.2 \\
\hline \multicolumn{5}{|l|}{ Biennial } \\
\hline Age $40-49$ years & -10.0 & -10.4 to -9.7 & -17.3 & -17.9 to -16.8 \\
\hline White & -10.8 & -11.2 to -10.4 & -17.8 & -18.4 to -17.2 \\
\hline Black & -3.2 & -5.6 to -0.8 & -10.2 & -14.0 to -6.2 \\
\hline Hispanic & -9.2 & -10.4 to -8.1 & -20.0 & -21.7 to -18.2 \\
\hline Asian & -9.4 & -11.2 to -7.5 & -16.7 & -19.5 to -13.7 \\
\hline Mixed & -7.9 & -8.9 to -6.9 & -14.9 & -16.4 to -13.3 \\
\hline Age $50-64$ years & -8.6 & -8.9 to -8.3 & -14.3 & -14.8 to -13.9 \\
\hline White & -9.3 & -9.6 to -9.0 & -14.8 & -15.4 to -14.3 \\
\hline Black & -4.5 & -6.2 to -2.8 & -8.3 & -11.2 to -5.3 \\
\hline Hispanic & -6.9 & -8.0 to -5.8 & -16.7 & -18.4 to -14.9 \\
\hline Asian & -6.3 & -8.1 to -4.5 & -14.5 & -17.4 to -11.5 \\
\hline Mixed & -6.9 & -7.7 to -6.2 & -11.7 & -12.9 to -10.4 \\
\hline
\end{tabular}

NOTE. Measure excluded diagnostic Current Procedural Terminology and Healthcare Common Procedure Coding System mammography codes 76090, 76091, G0204, and G0206.

*Estimated from Poisson generalized estimating equations regression, controlling for covariates listed in the text, by exponentiating the parameter estimate of the level change term, subtracting from 1, and multiplying by 100 . 
Table A5. Estimated Absolute and Relative Difference Between 2012 Observed Rate and 2012 Rate Predicted by 2005 to 2009 Trend by US Region

\begin{tabular}{|c|c|c|c|c|c|c|c|c|}
\hline \multirow[b]{2}{*}{ Age and Race } & \multicolumn{2}{|c|}{$\begin{array}{l}\text { Estimated* } \\
2012 \text { Rate (\%) }\end{array}$} & \multicolumn{2}{|c|}{$\begin{array}{c}\text { Predictedt } \\
2012 \text { Rate (\%) }\end{array}$} & \multicolumn{2}{|c|}{$\begin{array}{l}\text { Estimated* Absolute } \\
\text { Difference Between Predicted } \\
\text { and Observed } 2012 \text { Rate (\%) }\end{array}$} & \multicolumn{2}{|c|}{$\begin{array}{c}\text { Estimated } \neq \text { Relative Difference } \\
\text { Between Predicted and } \\
\text { Observed } 2012 \text { Rate }(\%)\end{array}$} \\
\hline & Rate & $95 \% \mathrm{Cl}$ & Rate & $95 \% \mathrm{Cl}$ & Difference & $95 \% \mathrm{Cl}$ & Difference & $95 \% \mathrm{Cl}$ \\
\hline \multicolumn{9}{|l|}{ Annual } \\
\hline \multicolumn{9}{|l|}{ Age $40-49$ years } \\
\hline West & 35.0 & 34.5 to 35.5 & 41.8 & 41.6 to 42.0 & -6.8 & -7.1 to -6.5 & -15.9 & -17.3 to -14.6 \\
\hline South & 39.0 & 38.7 to 39.3 & 42.4 & 42.3 to 42.5 & -3.4 & -3.6 to -3.2 & -7.8 & -8.6 to -7.0 \\
\hline \multicolumn{9}{|c|}{ Age $50-64$ years } \\
\hline West & 44.6 & 44.2 to 45.0 & 49.2 & 49.0 to 49.4 & -4.6 & -4.9 to -4.4 & -8.9 & -10.0 to -7.8 \\
\hline South & 47.1 & 46.9 to 47.4 & 49.9 & 49.8 to 50.0 & -2.8 & -2.9 to -2.6 & -5.1 & -5.7 to -4.5 \\
\hline Midwest & 49.5 & 49.1 to 49.8 & 52.0 & 51.8 to 52.1 & -2.5 & -2.7 to -2.3 & -4.7 & -5.5 to -3.9 \\
\hline Northeast & 47.8 & 47.3 to 48.4 & 53.3 & 53.0 to 53.5 & -5.4 & -5.8 to -5.1 & -10.0 & -11.3 to -8.7 \\
\hline \multicolumn{9}{|l|}{ Biennial } \\
\hline Northeast & 71.5 & 70.3 to 72.7 & 77.2 & 76.7 to 77.6 & -5.7 & -6.4 to -4.9 & -5.9 & -7.4 to -4.3 \\
\hline \multicolumn{9}{|c|}{ Age $50-64$ years } \\
\hline West & 72.7 & 71.9 to 73.5 & 79.0 & 78.7 to 79.4 & -6.4 & -6.8 to -5.9 & -9.0 & -10.3 to -7.8 \\
\hline South & 77.6 & 77.2 to 78.1 & 79.8 & 79.6 to 79.9 & -2.1 & -2.4 to -1.8 & -2.6 & -3.3 to -1.9 \\
\hline Midwest & 75.2 & 74.6 to 75.8 & 83.6 & 83.4 to 83.9 & -8.4 & -8.7 to -8.0 & -10.5 & -11.4 to -9.7 \\
\hline Northeast & 79.7 & 78.6 to 80.8 & 83.8 & 83.4 to 84.2 & -4.1 & -4.8 to -3.4 & -5.9 & -7.4 to -4.3 \\
\hline
\end{tabular}

*Estimated using the recycled predictions method from Poisson generalized estimating equations regression, controlling for covariates listed in the text.

tPredicted based on 2005 to 2009 screening trends and estimated using the recycled predictions method from Poisson generalized estimating equations regression, controlling for covariates listed in the text.

¥Estimated from Poisson generalized estimating equations regression, controlling for covariates listed in the text, by exponentiating the parameter estimate of the 2012 term, subtracting from 1, and multiplying by 100. 